\title{
The Economic Organization of Television in Cameroon: Challenges and Prospects
}

\author{
Olivier Bile \\ University of Yaounde II-ASSMAC, YMIS, Yaounde, Cameroon \\ Email: bileolivier@yahoo.fr, olivierbile0@gmail.com
}

How to cite this paper: Bile, O. (2020). The Economic Organization of Television in Cameroon: Challenges and Prospects. Theoretical Economics Letters, 10, 718-733. https://doi.org/10.4236/tel.2020.103044

Received: May 11, 2020

Accepted: June 27, 2020

Published: June 30, 2020

Copyright $\odot 2020$ by author(s) and Scientific Research Publishing Inc. This work is licensed under the Creative Commons Attribution International License (CC BY 4.0).

http://creativecommons.org/licenses/by/4.0/

\begin{abstract}
The purpose of this study is to assess the relevance of the economic organization of television in Cameroon. On the theoretical level, it presents the systemic and strategic analysis of how the modernization of the television landscape is constrained by deficiencies of considerable structuring and economic organization. The social science collection methods used for this purpose are of a qualitative type and are essentially based on direct observation and documentary research. In a comparative approach, it is a question of highlighting the constraining factors of the said organization viewed from a global perspective. This work reaches the conclusion that, beyond their deficits in terms of financial resources, televisions in Cameroon do not benefit from an organizational ecosystem favorable to the optimal deployment of their activities. It recommends an adequate structuring of this television ecosystem in order to resolve the structural problem of programmatic-economic austerity from which these televisions suffer.
\end{abstract}

\section{Keywords}

Economic Organization, Organizational Deficiencies, Structural

Organization, Strategic Organization, Advertising Organization

\section{Introduction}

Like any sector of economic activity worthy of the name, the television as a medium of communication needs to be credited with a robust and relevant organization in a given environment. Television emerged in the United States of America and Europe in the 1950s. Since then, its practices, professionals, techniques and modes of operation have not ceased to be improved, refined and so- 
phisticated. Just like other industries which work with their internal codes and logic which guarantee dynamism and vitality, the television industry has, over time, also had an extremely complex and refined system of organization, which has led to the tremendous development and even the remarkable technological, programmatic and economic emancipation of this sector in developed countries $^{1}$.

Familiar with this sector for almost thirty-five years for public television and twenty years for private television ${ }^{2}$, Cameroon remains however in a global situation of gross underdevelopment in this area (Bile, 2015b). One of the major roadblocks is the great economic precariousness in which most broadcasters operate. Given that the television-which comprises principally of programs (otherwise known as the raw material) on the one hand, and salaried professionals, especially in the private sector, on the other, are the main victims ${ }^{3}$-observers are bound to question the mode of economic organization of this sector. For, the television seems to smack of disorganization even from the outset.

From the advent of the first print media to today's web media, most studies on the media in Cameroon and Africa point to dysfunctions of all kinds, which very often arise from the lack of knowledge of basic good practices in the field. Since the introduction of liberalization in the communication sector in Cameroon from 1990-2000 (Tjade Eone, 2001), the local media landscape has witnessed a plural media offer. However, most analysts and observers have never stopped pointing out that the local media has always struggled with modernity. Through this work, we plan to study the methods of economic organization of television within the Cameroonian audiovisual landscape in the light of proven and current uses in the developed world. In a comparative approach, it is a question of highlighting the constraining factors of this organization. The objective is to bring out elements of knowledge and a vision likely to contribute to the modernization of the public media space in Cameroon. The modernization of this space is, undoubtedly also, an important prerequisite for the advancement of the democratization and development processes of the country (Tudesq, 1999). This study presents theoretical grids which support the assertion that the modernization of the television landscape is constrained by economic and organizational deficiencies. The methods used to explore this subject are of a qualitative type and are essentially based on direct observation and documentary research.

In terms of structure of the study, we will examine this sector of television ac${ }^{1}$ According to 2004 figures from TF1's director of acquisitions, Laurent Storch, each episode of an American fictional series costs, on average, $\$ 1.8$ million, 700,000 of which come from the local market and 1.1 million resales abroad. One can then imagine the global contribution of such a sector to the US foreign trade.

${ }^{2}$ Broadcasting activities of public television began with Cameroon Television (CTV) in 1985, while those of the private sector began after the decree of April $03^{\text {rd }} 2000$ setting the terms and conditions for the operation of private audiovisual communication enterprises.

${ }^{3}$ The share of production and program acquisition on the one hand, and that of salaries on the other hand, in relation to the overall resources of the channels, remains low for most channels whose efforts are more focused on material investment or in other unproductive operating expenses. 
tivity in Cameroon from the point of view, successively, of its structural organization, its strategic organization in the sphere of television companies, its strategic organization in the state sphere, and finally of its advertising organization and in terms of private financing.

\section{Theoretical Framework}

\subsection{Strategic Analysis}

It is a paradigm of the sociology of organizations proposed by Michel Crozier and Erhard Friedberg (1977). This theory is an extension of the structural-functionalist theses. The actor, in the sense of Crozier-Friedberg, is one whose behavior helps to structure a field, that is to say, to build regulations. We seek here to explain the construction of rules (the social construct) from the game of empirical actors; interested calculators. These actors have rationality, although it is limited. They are autonomous and interact in a system that helps structure their games. They intervene in a system, the organization, which must and can adjust to contingencies and changes of various kinds. However, there is no natural adjustment, only constructs, which presupposes the presence of intentionality. For these two authors, these assumed mechanisms constitute the concrete system of action.

The concept of television landscape analyzed in this work refers to an idea of pluralism and diversity which, for a few years already, characterizes the audiovisual sector in Cameroon. In such an environment, each radio or television must have its own objectives and goals. Each of these actors should develop their particular strategies, based on the determinants of media modernity. The interest of this study also lies in its ambition to raise awareness of such a need. It encourages the players in this audiovisual landscape to develop more specific strategies in the competitive world-wide universe which is now theirs as an existential imperative. Participation in the forums of modern communication and media is ideal.

\subsection{Systemic Analysis}

In the American army during the Second World War, systems analysis aimed at studying the means of better coordination of decisions in an organization. The system would then be defined as an organization of interdependent elements operating according to self-regulatory processes. After the war, the systems approach was applied to the management of businesses and public administrations. And long before these practical uses, Ludwig Von Bertalanffy had linked the biological and physical systems. Under the influence of cybernetics and communications theory, he developed a systems theory based on mathematical logic. In the 1960s, researchers such as Almond, Easton and Deutsch took an interest in the decision-making and regulatory processes implemented in political life and really gave birth to systemic analysis by proposing for the first time, a general 
model of study of societies based on a set of systems.

The global economic organization of television media in Cameroon as a declared objective of this work also plunges us into systemic analysis insofar as these media are understood as organizations implementing various levers intended for the purpose. It was clearly a question here of identifying the main factors whose interaction could lead to the purpose which is an optimal organization of the said media. Certainly none of these factors, taken in isolation, can do this. I consider that it is thanks to a dynamic interaction operating in a systemic logic that the various determinants could allow the achievement of the expected positive results. The Cameroonian audiovisual media, in the various studies devoted to them through my work, are indeed considered, as systemic; as structured constructions or systems whose components are interrelated. These systems are themselves related to other external systems, the whole constituting the audiovisual landscape. This dynamism, both internal and external, in search of balance and performance represents the perspective in which these media organizations should operate. If indeed they wish to embark on a satisfying quest for modernity.

This research work was carried out within the framework of the Yaounde Media and Information School of the University of Yaounde II-ASMAC (Advanced School of Mass Communication) in Cameroon.

\section{The Structural Organization}

\subsection{The Issue of the Television Business Project}

The structural organization, opposed to another form of organization that would be cyclical, refers here to a set of fundamental determinants on which the economic organization of television in Cameroon is based. It is therefore all about the heavy parameters on which this economy is based, and which consequently governs its most essential movements. While it is well accepted that television and the media in general generate an economic activity like the others (Toussaint Desmoulins, 2015: p. 7) ${ }^{4}$, it is equally true, if not equally important, to underline the considerable specificities that distinguish the televisual economic activity from other more classical and traditional economic activities ${ }^{5}$.

Cameroonian TV entrepreneurs who often break into this sector of activity tend to be driven by the fact that television is a business like any other. In the wake of the wind of audiovisual liberalization in the 2000s, a kind of fashion of creating its own chain occurred. It has worked to stage operators with some capital, but unfortunately, often lacking the necessary media and artistic culture in ${ }^{4}$ It includes the same parameters of importance of means implemented, diversification and concentration of activities, then those of market penetration and development barriers, but also those of internationalization of trade and capital.

${ }^{5}$ This economy is characterized by the very fast perishability of some of its products, an expensive production of prototypes, the high cost of distribution, a specificity of the demand and the market inducing in particular a random valorization, a lack of price of market, and a dual market: advertising and joint product, a significant influence of public authorities. 
this area. Their initiatives are usually also initiated without any prior viability investigation. Many of them went bankrupt after a few years, or just disappeared $^{6}$. Others are struggling to survive and vegetate, unable to challenge themselves, restructure and redeploy more effectively. Yet audiovisual production relies above all on talent. Productivity gains in terms of creativity, and more generally in the arts, are by nature limited since they rely first on the ability of men to invent and imagine (Danard \& Le Champion, 2005: p. 33). The logic here is often that of the quest for immediate financial profitability, all things that can only undermine the cultural vision of an extremely sensitive activity, itself based on the immateriality of its products.

\subsection{The Flow Paradigm}

This policy of seeking immediate financial profitability has two serious consequences for the operation of these televisions. On the one hand, the predominant orientation towards a "low cost" television model emphasizing the contents of flows to the detriment of those said of stock. The media economy of the flow that mobilizes so-called perishable products (Toussaint Desmoulins, 2015: p. 18) inevitably leads to the establishment of an unbalanced television ecosystem where the "speech", the talk and the permanent chatter that Mactar Silla (1994) already evoked ${ }^{7}$, take precedence over a more diversified offer in audiovisual genres, and therefore more attractive and more structuring for the broadcasting scene in general.

The perishability of media products ${ }^{8}$ is essentially associated with information programs which occupy only a small part on a generalist type of antenna. Even in the category of broadcasts that include information, sports, variety, debates, entertainment, talk show, reality TV and games that, like the press hot news, lose practically any value once broadcast, the spectrum of Cameroonian TV antennas is significantly restricted on the side of information, talk show and various forms of debates whose production costs are deemed low. By their obsolete nature-obsolete after their broadcasting often live, such content, poor in cultural value, which are more like video chatter, devoid of heritage value, do not enjoy the noble status of audiovisual work.

\subsection{The Paradigm of Stock}

Yet, television is not supposed to offer only perishable products from the stream. It also offers a range of other products called stock, whose characteristic is not to ${ }^{6}$ The pioneer chain TV Max of the early 2000s quickly disappeared after judicial vicissitudes that opposed CRTV for a broadcasting rights case. Others like New TV, Ariane, Canal2 Infos, Camnews 24 , among others, have simply disappeared from screens after a bankruptcy never announced to the public. Apart from 4 to 5 channels trying to maintain themselves, the audiovisual landscape reports a great instability.

${ }^{7}$ Citing a Japanese diplomat, Mactar Silla, former director general of the STV group in Cameroon, already pointed out this structural drift of African television in 1994.

${ }^{8}$ While the food or chemical industries have found ways to preserve food, liquids and gases, no one has yet managed to keep its freshness to a new two-day old. 
be perishable while retaining an economic and heritage value over time. The production of works of stock requires significant financial means: more than $30 \%$ of the investments of television channels in France (Danard \& Le Champion, 2005: p. 64). Less related to news, their distribution can be repeated and sold at will, depending on the contractual terms and conditions set in the context of the sale of the broadcasting rights of the said productions of stock. Fiction $^{9}$, cinematographic works, documentaries ${ }^{10}$, animated films and some feature magazines belong to this category of programs. Originally, along with information and sports, the recent shift from shortage television to television of abundance (Danard \& Le Champion, 2000), the types of stock have largely contributed to the specialization, substantial diversification and growth of contemporary television offerings.

By becoming overwhelmingly involved in the flow model, Cameroonian television has, ipso facto, banned access to these virtues and benefits of the structuring television model of the stock. It is always built around the production of stock, an entire economic chain integrating the many actors involved at various levels. In the case of fiction, the stock also offers the perspective of recurring programs such as series, mini-series, soap operas and animated films that retain an audience for a while, while allowing reruns. It ensures consistency of content and appeal, allowing the programmer to rely on predictable and stable audience outcomes, which in television is vital and essential. The fabric of local fiction production in Cameroon remains embryonic. The production of cinematographic films and television dramas is characterized by a high degree of scarcity and, where appropriate, a very low level of competitiveness which does not favor exportation.

\section{The Strategic Organization in the Sphere of Companies}

\subsection{The Lack of Market Study}

The strategic organization is understood here in terms of all the measures relating to the television companies themselves, at the top of their management teams, which are intended to improve their functional efficiency and economic dynamism. In the absence of the necessary audiovisual engineering, the promoters mobilize the infrastructure and technical equipment, sometimes with considerable resources in the service of projects which have not questioned the expectations and aspirations of the viewers. The classic model of the flow-oriented generalist channel and its corollary of "speech" already evoked, becomes totally ${ }^{9}$ Fiction is considered the flagship program of television. For example, among the 100 best French audiences in 2004, there are 51 fictions. In terms of performance, the balance of fiction is positive and indicative of a match between supply and demand of the public.

${ }^{10}$ Noble genre on television, the documentary generally relates to discovery and knowledge. It is a difficult genre because little bearer of massive audience like the affectionate generalist hertzian chains. Anchored in the heart of the real, it contrasts with the fiction that encapsulates the imagination. It is however in renewal lately with the emergence of the documentary of creation which mixes real and imaginary. 
dominant, and in the long run, boring. However, the programmatic model of specialization ${ }^{11}$ and the setting in themes of the offer is already well known to the local public who for a long time, has been supplied by foreign complement channels ${ }^{12}$, which also seem very interested by the rare initiatives of the same nature in the local audiovisual landscape ${ }^{13}$. The diversification of the offer resulting from the specialization is therefore a vital issue.

\subsection{Excessively Internalized Production}

The production system governing local television operates almost in a vacuum. This excessive internalization of production is carried out in the studios of various channels, often live, by the technical and editorial production teams of each channel taken separately. With the exception of telenovelas type fictions often acquired through the mechanism of bartering with some advertisers, or even local fictions granted at very low costs by some independent producers of the place, the overwhelming majority of the program offer are made of talk-show finally quite similar, which induces a quasi-autarkic operation of the local chains. The internalized production model is also generating considerable weight that is not conducive to a dynamic deployment of structures.

The vitality of a television channel is nowadays also dependent on the variety of its sources of program supply. Great Britain is one of the first European audiovisual markets where the use of subcontracting towards independent and local producers has become fairly systematic (Bile, 2015a: p. 44). The BBC, British public television, has been able to take advantage of its institutional constraint outsourcing $25 \%$ of its production by outsourcing programs requiring structures less competitive than those of its technological arsenal. It is the generalization of this principle that has allowed it to develop its famous principle of "Producer Choice"14.

Even in Spain, where RTVE, a public television channel trying to follow the BBC path, is handicapped by the massive internal production logistics it has, the need for lower fixed costs has translated into increased use of Spanish television by independent small companies specialized in types of programs (Achille \&

${ }^{11}$ See, Olivier BILE, The programmatic model of Cameroonian television: Between generalism and specialization, Rhumsiki-Presses Universitaires de Valenciennes, $\mathrm{N}^{\circ} 2,2015$.

${ }^{12}$ Channels such as CNN, LCI, BFM TV, CNews in the field of continuous news as well as many others operating in the sport or fiction segments have long been watering Cameroonian households via cable and satellite packages.

${ }^{13}$ Some attempts to rush into this paradigm of specialization are spotted in some local broadcasters. The Canal 2 group, with Canal 2 Movies or Canal 2 Info, that does not seem to have kept the promise of flowers. Boom TV, the musical arm of the STV group. The brand new and promising CRTV News and CRTV sports from CRTV.

${ }^{14}$ The central idea for developing the BBC's competitiveness revolves around a constant competition between internal and external resources and means of production. Whenever the producer of a program can find less expensive solutions outside, he is forced to make this choice.

In 2005, the French production market already had nearly 1100 companies. These are generally small, under-capitalized structures that specialize in a specific type of production: documentaries, games, recording shows, reports, magazines, reality shows, fiction, advertising, etc. 
Ibanez Bueno, 1994).

In France, as in most other Western European countries, public authorities have established legislation to promote the development of the fabric of independent producers. This has led to the enunciation of obligations made to broadcasters with regard to the promotion of independent production. The economic objective of the said obligations is to consolidate and develop an endogenous fabric of audiovisual production companies capable of ensuring the diversity of production and the preservation of the values and identity of these countries. In France, orders are thus encouraged from broadcasters to independents (Danard \& Le Champion, 2005: p. 28). Two-thirds of the orders for audiovisual works on terrestrial channels must be passed on to independent production companies. The system of independent production, initially associated with the production of the works of stock, has considerably extended to the production of the flux programs through the emergence, in the 1990s, of the setting of the "TV hosts-producers" (Bile, 2015b: p. 32). This new principle of operation and management ${ }^{15}$ consists, for the channels, to entrust the production of certain programs of their programming grid to famous TV hosts. The latter, sometimes formerly employees of the said channels, are incorporated through an independent company. The advantage lies in the fact that the channels no longer have the constraint of managing all the contents of their grid, and focus more on the issues of programming strategies and competition in terms of audience. On the other hand, programs produced gain in efficiency and quality. Private producers use the best professionals and technical structures for the preparation of their programs.

\subsection{Strategic Mechanisms of Production}

The raw material of a television channel lies in the programs. Just as uranium has strategic value for the nuclear industry, programs have the same key value for the television industry. The latter therefore has the obligation to deploy all the necessary engineering to ensure a sustainable and advantageous supply of programs to feed its grid. A television channel may invest in the acquisition of the rights of an audiovisual program in two ways, either by purchasing the program in the form of pre-purchase or purchase, or in the form of co-production shares. Legally, purchases and pre-purchases confer the same prerogatives. The pre-purchase is a pre-financing of the work because it is made before filming, while the purchase of rights occurs after the complete realization of the product. The purchase of rights corresponds to a right of representation, that is to say, to a right of diffusion within a precise framework.

\footnotetext{
${ }^{15}$ According to Marc Tessier, former president of the France Televisions group, the strategy initiated by the programming of TV hosts-producer programs has enabled the Group to modernize its image, increase its advertising revenues, invest in quality programs, and to assume a programming fully justified by its object but costly in terms of audience. For example, the company Air Production belongs to the host Naguy, Reservoir Prod to Jean Luc Delarue, Magic TV to Patrick Sébastien, Coyotte Production to Christophe Dechavanne.
} 
A co-producing share is a title to the work, and confers on its owner the benefit of any revenue generated by the subsequent exploitation of the work. Holding a co-production share on a work also means assuming the risk of financing, especially in case of budget overruns (Danard \& Le Champion, 2005: p. 27). The great programmatic origin, in quantity and quality, of local television antennas is also due to the lack of knowledge of these different strategic production devices. Collaboration between broadcasters and independent producers is essential. The pre-purchase allows the producer to complete the financing of its production while allowing the broadcaster to expect exclusive use for a certain period of time. Co-production also brings together resources to finance a work by two or more partners. The only practice in force which is independent of Bartering, is the occasional and derisory purchase of the rights of some mediocre local fiction-an approach that cannot guarantee the development of the audiovisual landscape.

\section{Strategic Organization in the State Sphere}

\subsection{Structuring and Regulation of the Sector}

As a regulator of all forms of economic activity within a country, a strategist state has the duty to take all the measures within its sovereign domain of competence, in order to favor the optimal development of an economic sector just as it should with the audio-visual sector (Balle, 2007). This strategic regulation therefore aims to work to organize, structure and build the audiovisual sector, so as to confer the best operational efficiency, aesthetic-artistic and ultimately economic and cultural features on it. In advanced societies, this organizational modality is crystallized through the technology of the specialization of the actors.

\subsubsection{The Requirement of Specialization}

The Cameroonian audiovisual sector, more than thirty years after its emergence, nearly twenty years after its liberalization, remains in a logic that ignores the dynamic potential of specialization by sector of activity. Some of the actors in this sector simply do not exist, while others have a rather anecdotic existence. Worse, it is often the phenomenon of excessive concentration of several functions in the hands of the same actor that often poses a problem. It is not uncommon to find operators acting both as a screenwriter, producer, actor, distributor and financier for the same work of fiction for example.

\subsubsection{The Prerequisite of Writing}

The writing activity of the scenario is fundamental for the works of stock and especially for the fiction. The specialization of this function in Hollywood cinema, often with colleges of several writers for the same work, justifies a large part of the attractiveness. The quality, originality and power of the script are essential factors in the success and competitiveness of a fictional work, be it a film, a TV movie, a series, a soap opera or an animated film. This is why a producer's commitment to a scriptwriter will always depend on these criteria. 


\subsubsection{The Keystone of Production}

The producer is a conductor who federates and manages talents, from the finalization of the scenario to the final post-production. He enters into relationship with a screenwriter, initiator of the work, and validates the final written version. He then takes the initiative of materializing the project and assumes financial, technical and artistic responsibility ${ }^{16}$. The development of the fabric of independent producers is generally a good indicator of the vitality of the audiovisual sector within a state. Conversely, the weak fabric of independents is often indicative of audiovisual underdevelopment. Cameroon has about fifteen private production companies, a small portion of which regularly deals with broadcasters. These producers, most of which operate in the field of fiction, are seen as stubborn hustlers, since their means of production often come from everyday miracles. On the commercial front, the lack of a local audiovisual market restricts the supply of private programs, and confines the few independent productions to accept, if necessary, acquisition conditions on purely anecdotal terms ${ }^{17}$.

\subsubsection{A Regulatory and Institutional Framework Conducive to Production}

At the institutional level, the lack of a state support mechanism for local private production does not favor the development of this sector. In the absence of a legal framework favorable to audiovisual production, this area is stagnant and remains in a state of gross underdevelopment. To encourage French cultural diversity, for example, the legislator is working to create the legal conditions for the development of an audiovisual production market by forcing television channels to use French outside service providers to the manufacture of their programs. They are required to devote part of their programming to the broadcast of European audiovisual works and French original expression ${ }^{18}$, in order to promote cultural diversity (Guibert et al., 2016) on French channels. We are talking about broadcast quotas.

In addition to broadcasting obligations, these channels must invest in the production of new audiovisual works, with a view to boosting the French production industry ${ }^{19}$. They are subject to order obligations called production quotas. In Great Britain these production quotas represent $25 \%$ of the overall production budget of the $\mathrm{BBC}$, which is a public television. The channels must

\footnotetext{
${ }^{16}$ In order to effectively accomplish its missions, the producer is accompanied by a staff dedicated to production including producer delegate, executive producer, associate producer, production manager, managers, etc. This team can be more or less densified depending on the nature or importance of production.

${ }^{17}$ Apart from the very occasional special affection account of the Ministry of Culture whose volume of grants to film producers can simply be considered anecdotal.

${ }^{18}$ This priority distribution of local works mechanically promotes the economic expansion of national production companies, which sell their products at relatively high costs.

${ }^{19}$ In addition to the revenue earned on the sale of finished works, French producers are eligible for a set of national, European and sometimes local public mechanisms guaranteeing them substantial subsidies for a comfortable realization of their works. The Program Support Account for the National Center for Cinematography is one of the most emblematic.
} 
therefore participate in the pre-financing of audiovisual works (Danard \& Le Champion, 2005: pp. 25-26). A large part of these resources indirectly collected by the State is redistributed through institutional funds such as the Program Support Fund in France (COSIP). This fund is financed by an 11\% tax on cinema admission tickets, a $5.5 \%$ tax on the turnover of public and private television channels (fees, advertising, subscriptions) and a tax of $2 \%$ on DVD sales and rentals. In 2005, these taxes boosted the support account by 490.96 million Euros. $46 \%$ of the support account is used for aid to audiovisual programs, the rest being intended to support the film industry. Some other private mechanisms aimed at boosting the audiovisual and cinematographic sector have also been put in place ${ }^{20}$.

\subsubsection{The Accessories of Production}

Another segment of the audiovisual sector includes production aids integrating artistic agents and technical industries. The artistic agents represent the professionals of the "talents" that they manage: performers, writers, filmmakers, directors, composers of music. They negotiate the contracts of engagement which they ensure the follow-up and the good execution. Technical industries are a network of companies that provide producers with the material means to produce works. These companies rent filming equipment (cameras, lighting, car controls, etc.). They also offer various services covering production and post-production ${ }^{21}$. These auxiliaries of production simply do not exist in Cameroon. Professionals are thus led to manage their own careers and their very rare contracts on the basis of extremely precarious conditions in an environment where the unions of these intermittencies of culture are simply non-existent. The absence of technical industries worthy of the name has a considerable impact on the quality of local audiovisual services, especially those from private operators. Many other links in the audiovisual channels are thus absent from the local production system, all of which undermine the overall quality of local products and programs.

\subsubsection{Distribution and Trading of Audiovisual Rights}

The distribution or trading of the rights of works is another sector of activity that requires specific skills. The author-producing actor in Cameroon is often also an authorized distributor of his own works.

\subsubsection{The Downstream and Strategic Sector of Diffusion}

The key link of the broadcasters is at the heart of the industry. It consists of television channels that play a vital role in the economy of audiovisual production.

${ }^{20}$ In addition, producers in these countries also benefit from mechanisms such as private equity funds called Film and Audiovisual Industry Financing Companies (SOFICAs), as well as specialized private banking institutions that allow them, via public guarantee such as the Institute for Financing Cinema and Cultural Industries (IFCIC), which facilitate the mobilization of resources dedicated to production in a general way.

${ }^{21}$ The French production company (SFP) created in 1974 following the bursting of the ORTF has a state-of-the-art technical arsenal that receives and facilitates most of the French studio productions. 
They order programs for producers according to precise specifications, monitor their production, distribute them and often exploit the derived rights. The economy of television channels has become much more complex in recent years with the emergence of broadcasters whose economic model is no longer the same. The public terrestrial channels, mainly financed by the audiovisual license (Toussaint Desmoulins, 2015: p. 103) compete with the commercial private channels as well as the thematic channels of the cable and the satellite. In Cameroon, this exclusivity of the public broadcasting license is also valid. As elsewhere, this fee is supplemented by additional advertising revenue collected by CRTV's advertising agency, the Cameroon Marketing and Communication Agency (CMCA). As for private commercial channels, they live exclusively on advertising and sponsorship revenue. Their general setup derives its cause from the reality of the underdevelopment of the advertising culture in force in the country.

\subsection{The Study of Channel Audience}

As for the strategic sector of the audience study, it is supposed to work to highlight and evaluate the economic competitiveness of broadcasters. It suffers here from its strong extraversion and from a considerable and prejudicial irregularity of the rare studies carried out (Bile, 2019).

\subsection{The Critical Issue of Studies and Statistical Data}

The local audiovisual system also suffers from the lack of statistical data and economic studies to better understand the sector. However, the collection and provision of such data is also the domain of the State and academic research institutions. It is indeed crucial to be able to grasp realities as diverse as the global and individual resources of broadcasters, the share between turnover and production budgets of channels, the volumes of resources generated by independent producers, advertising and audiovisual levy, the impact of the audiovisual sector in terms of employment, etc. This mass of data is indeed essential for the elaboration of real public policies in favor of a sector still neglected.

\section{Advertising Organization and Private Financing of Channels}

\subsection{An Economy of Austerity}

The advertising organization is understood here as the set of private financing mechanisms which, excluding the public license fee, allow different broadcasters to mobilize various resources to make their structures work. One of the first characteristics of this local advertising market is its poverty. The very low cost of a commercial on a leading channel like CRTV, the weak commitment of local companies in the function of audiovisual advertisers, the low advertising culture itself dependent on the low quality of television content, generate the reality of a rather underdeveloped advertising market. Comparatively, where the cost of a TV spot can vary from 2000 to more than 100,000 euros in France, this same 
spot can oscillate around 100 to 600 euros maximum only on the local market. The few advertisers available are those engaged with most major broadcasters, many other companies in the place preferring other advertising methods, when they simply do not feel the urge to invest.

The consequence of such a context is a very strong offer of global advertising space for a volume of available resources still declining. The low level of advertising revenue, in the absence of other funding mechanisms for broadcasters and private producers, does not, in turn, support a significant investment in programs that end up painfully suffering from an unsustainable audiovisual system surviving on a drip. It's squaring the circle. This results in a precarious and unstable socio-professional environment, particularly for employees of the chains, who, always in search of the least bad payer, have no choice but to settle in logic of permanent transhumance between the different local private audiovisual structures.

\subsection{A Market with a Lack of Innovation}

This advertising market is also characterized by its primary and uninventive aspect. The main instrument of this activity remains the classic advertising spot whose local production always suffers from a considerable concern for creativity, a condition of its attractiveness. However, there are advertising alternatives in terms of space, to ensure such benefits otherwise.

Sponsorship or patronage, unfortunately very little practiced at the local level, is for an advertiser, to contribute to the financing of a program (financial participation or gift offer) in return for the display of his name or identifying signs of his company. It allows a presence, in principle, in or around a program. A television can also rent time slots (often late at night) of low attraction, intended for institutional communication. Bartering is one of the few processes very widely used by local channels because of its advantages from the point of view of free program provision. It consists for an advertiser, a producer or a distributor, to provide a broadcaster, a turnkey program in exchange for advertising screens that he uses in his favor or for which he negotiates the sale. This system is at the origin of soap operas sponsored in the United States by the laundry. We also find here, in a marginal way, a certain caste of community channels, religious vocation, living essentially from patronage. Other commercial revenues may be earned through the sale of programs belonging to chains producing or co-producing heritage content. Other recipes can finally come from derived rights. This is the transfer of the rights of all or part of the characteristic elements of a program, for the manufacture of objects of clothing, toys, the edition of disks, cassettes, books, etc. (Toussaint Desmoulins, 2015: p. 113).

\subsection{The Lack of Regulatory Devices to Regulate the Advertising Broadcast}

The local advertising operation also manifests a global situation of disorder due 
to a blatant defect of regulatory devices designed to regulate the broadcast of advertising on television. This dissemination of advertising meets only the requirement to accumulate the maximum possible revenue, no real legal standard having been enacted by the competent authorities to discipline and streamline the use of advertising. Public television, which already enjoys the support of the public audiovisual license, has no regulatory restrictions on its access to the advertising pie. Private television channels, already precarious because they are not allowed to pay royalties, cannot benefit from more favorable access to the advertising market. In this context, they also throw themselves into an erratic, mercantilist and unlimited consumption of advertising, all of which do not fail to have harmful effects on the diffusion of the programs themselves ${ }^{22}$.

However, the National Council of Advertising, public regulatory body of the sector, should set regulatory measures for the dissemination of advertising. In France, the broadcast of advertising on television is regulated by a decree laying down the general principles of advertising and sponsorship ${ }^{23}$. This decree clearly defines the rules for the distribution of advertising screens. These must be clearly identified in a sound and visual way. Cinematographic and audiovisual works cannot be interrupted by advertising screens on these public channels, unlike private ones. Only programs providing sports broadcasts with intervals may insert advertising in these idle times. Programs other than audiovisual works, such as varieties, stage programs and games, may be interrupted by advertising only when they have autonomous parts and are broadcast before $8 \mathrm{pm}$, such as Télé Matin on France 2. On private channels, commercials can be inserted in programs. However, a period of 20 minutes must be respected between two advertising breaks within the same program. Cinematographic and audiovisual works may only be cut once, except when the film lasts more than 150 minutes. In this case, it may be subject to further cuts after prior approval of the Superior Council of Audiovisual (SCA). In all cases, the duration of advertising screens is limited by regulation according to the nature of the channels. For example, on the subject of authorized advertising volume, let us examine the cases of public France 2 and private TF1. According to the SCA, France 2 enjoys a maximum daily average of advertising per hour of 6 minutes and a maximum duration for a given hour of 8 minutes. TF1, for the same criteria has respectively 6 and 12 minutes (Danard \& Le Champion, 2005: pp. 53-54). This time difference expresses the will of the SCA to grant more margins of advertising manipulations to the private channel TF1 which, being not eligible for the public royalty, must also fight on the advertising market and the audience against TF1. At the local ${ }^{22}$ On some big variety shows of CRTV and Canal 2, we have been able to pick up a superabundance of advertising that defies the imagination. For their flagship two-hour Sunday programs, advertising that take various forms of advertising sometimes takes up to $60 \%$ of the airtime.

${ }^{23}$ This television broadcast of advertising is governed by Decree No. 92-280 of 27 March 1992 laying down the general principles of advertising and sponsorship. It establishes precise rules on the content of advertising messages controlled by the ASC. It also defines the rules for distributing advertising screens. 
level, these types of mechanisms introduce equity in access to the advertising market, while disciplining broadcasters in terms of business ethics, simply do not exist. They are nevertheless indispensable for the civilization of the entire audiovisual landscape. Moreover, lack of regular tools to measure the audience of broadcasters, the advertising pricing clearly does not correspond to the actual performance of the various media involved. This random and irrational functioning of the advertising market is in turn not likely to generate the virtuous circle expected: strong and stable audience-quality programs-increased advertising-investment in programs-satisfaction of viewers.

\section{Conclusion}

This work consisted in examining the modalities of economic organization of television in Cameroon, in the light of the habits and customs in force in advanced societies. The analysis leads us to the result that the modernization of the television sector is burdened by significant organizational constraints on the economic level. A strategic organization in the different segments studied would improve the overall performance of the television ecosystem. If a good economic organization of the sector has vocation to optimize the functioning of the structures therein, it should however be underlined that the fate of the television in question is also dependent on factors relating to various other considerations. This is the place here to underline the limits of the present study residing essentially in the virtual absence of researchers engaged in this field of the socio-economic composition of the audiovisual media in Cameroon, even as this sector is experiencing a significant boom in the recent years. The Cameroonian media environment also reveals a glaring deficit of academic studies and statistical data likely to shed light on this media governance. This is why it has been quite difficult to mobilize more recent documentary sources. That said, the interest of this contribution, which remains applicable to most African countries, is to pave the way for a tradition of study oriented towards these economic questions related to the specific sector-television, that is so needed in our developing societies.

\section{Conflicts of Interest}

The author declares no conflicts of interest regarding the publication of this paper.

\section{References}

Achille, Y., \& Ibanez Bueno, J. (1994). Les télévisions publiques en quête d’avenir (327p.). Grenoble: Presses Universitaires de Grenoble.

Balle, F. (2007). Médias et société(13th ed.). Paris: Montchrestien.

Bile, O. (2015a). Le modèle programmatique des télévisions camerounaises: Entre généralisme et spécialisation. In Rhumsiki-Presses Universitaires de Valenciennes (No. 2, pp. 139-149). 
Bile, O. (2015b). Les télévisions africaines face au défi de la modernit. Paris: L'Harmattan.

Bile, O. (2019). Mesure de l'audience et évaluation de la performance des médias audiovisuels au Cameroun. In Fréquence Sud(No. 22-23). Yaoundé: Université de Yaoundé II-ESSTIC.

Crozier, M., \& Friedberg, E. (1977). L'acteur et le système. Paris: Seuil.

Danard, B., \& Le Champion, R. (2000). Télévision de pénurie, Télévision d’abondance: Des origines à Internet. Paris: La Documentation française.

Danard, B., \& Le Champion, R. (2005). Les programmes audiovisuels. Paris: La Découverte, Coll. Repères.

Guibert, G., Rebillart, F., \& Rochelandet, F. (2016). Médias, culture et numérique: Approches socio-économiques. Paris: Armand Colin.

Silla, M. (1994). Le paria du village planétaire ou l'Afrique à l'heure de la télévision mondiale. Dakar: Nouvelles Editions Africaines du Sénégal.

Tjade Eone, M. (2001). Démonopolisation, Libéralisation et Liberté de Communication au Cameroun: Avancées et reculades. Paris: L'Harmattan.

Toussaint Desmoulins, N. (2015). L'économie des médias (9th éd.). Paris: PUF.

Tudesq, A. J. (1999). Les médias en Afrique. Paris: Ellipses. 